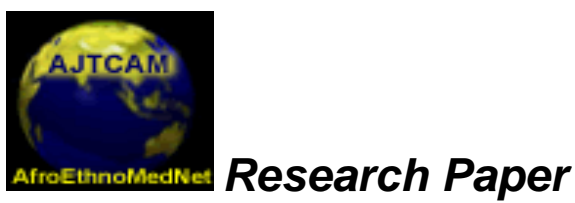

Afr. J. Traditional, Complementary and Alternative Medicines www.africanethnomedicines.net

ISSN 0189-6016@2008

\title{
EVALUATION OF THE ANTIOXIDANT EFFECTS OF ZIZIPHUS MAURITIANA LAM. LEAF EXTRACTS AGAINST CHRONIC ETHANOL-INDUCED HEPATOTOXICITY IN RAT LIVER
}

\author{
Dahiru, $\mathrm{D}^{1^{*}}$. and Obidoa, $\mathrm{O}^{2}$ \\ ${ }^{1}$ Department of Biochemistry, Federal University of Technology, Yola \\ P.M.B. 2076 Yola, Adamawa State, Nigeria \\ ${ }^{2}$ Department of Biochemistry, University of Nigeria, Nsukka \\ Enugu State, Nigeria \\ *Email: ddahiru2000@yahoo.com; Phone: 08025526252
}

\begin{abstract}
Chronic alcohol ingestion is known to increase the generation of reactive oxygen species (ROS), thereby leading to liver damage. Antioxidant enzymes act individually or in combination to reduce or counter the effect of these ROS. Chronic administration of alcohol at $(40 \% \mathrm{v} / \mathrm{v}, 1 \mathrm{ml} / 100 \mathrm{~g})$, for 6 weeks showed a significant $(p<0.05)$ elevated levels of alanine aminotransferase (ALT), aspartate aminotransferase (AST), alkaline phosphatase (ALP), and total bilirubin (TB). There was also a significant $(\mathrm{p}<0.05)$ decreased levels of catalase, glutathione peroxidase, glutathione reductase and superoxide dismutase compared to control rats. Pretreatment of rats with $200,400 \mathrm{mg} / \mathrm{kg}$ body weight of aqueous leaf extract of Ziziphus mauritiana or $100 \mathrm{mg} / \mathrm{kg}$ silymarin resulted in a significant $(\mathrm{p}<0.05)$ decreased levels of ALT, AST, ALP, and TB with levels of catalase, glutathione peroxidase, glutathione reductase and superoxide dismutase showing a significant $(\mathrm{p}<0.05)$ increase compared to group administered alcohol only. Histopathology of rat liver administered with alcohol only resulted in severe necrosis, mononuclear cell aggregation and fatty degeneration in the central and mid zonal areas which was a characteristic of a damaged liver. Pre-treatment with the aqueous extract of Ziziphus mauritiana or silymarin reduced the morphological changes that are associated with chronic alcohol administration. The presence of tannins, saponins and phenolic compounds observed in the plant extract could be responsible for the observed effects of decreasing the levels of injured tissue marker and lipid peroxidation.
\end{abstract}

Key words: $\quad$ Antioxidant enzymes, Ziziphus mauritiana, alcohol, liver damage

\section{Introduction}

Chronic alcohol consumption leads to several metabolic disorders including hepatic and extra hepatic diseases (Lieber, 2000). Although excessive acute or chronic ingestion of alcohol represents a serious hazard to health, alcohol is still the second most widely used psychoactive substances in the world, after caffeine (Puzziferri et al., 2000).

About $80-90 \%$ of ingested alcohol is metabolized in the liver, where alcohol is oxidized to acetaldehyde (Kim and Shin, 2002; Pronko et al., 2002). The process is catalyzed by three different enzymes: alcohol dehydrogenase (ADH), microsomal ethanol metabolizing system (MEOS) and acetaldehyde dehydrogenase (ALDH) (Lieber, 2000). Since acetaldehyde is much more toxic than alcohol, it is associated with a lager number of the metabolic abnormalities in liver disease induced by alcohol (Vidal et al., 1990; Quertemont, 2004).

Although the pathogenesis of alcohol-induced liver disease remains the subject of debate (Freidman, 1983), one factor that has been suggested as playing a central role in many pathways of alcohol-induced damage, and which has been the focus of much research is the excessive generation of molecules called free radicals, which can result in a state called oxidative stress (Wu and Cederbaum, 2003). Numerous studies have 
indicated that excessive ethanol intake induces the mass production of free radicals in the body, which are considered to be associated with alcoholic liver disease (Ishii et al., 1997). Furthermore, a number of experimental studies demonstrated that either acute or chronic alcohol administration to experimental animals increases the formation of lipid peroxidation products, such as malondialdehyde (MDA), and decrease liver tissue levels of antioxidants, such as glutathione, ascorbic acid and antioxidant enzymes (Nadro et al., 2006; Das and Vasudevan, 2006). Despite the important progress made in understanding the pathogenesis of alcoholic liver diseases current therapies for this disease are not effective. Recent research has focused on the development of antioxidant drugs that successfully correct the fundamental cellular disturbances resulting from excessive alcohol consumption (Saravanan et al., 2003; Zhou et al., 2003).

Ziziphus mauritiana belongs to the family Rhamnaceae (Michel, 2002). The ripe fruit of the plant are mostly consumed raw, but are sometimes stewed, while young leaves are eaten in Indonesia (Morton, 1987). The leaves are applied as poultices and are helpful in liver troubles, asthma and fever (Morton, 1987; Michel, 2002). Recently the hepatoprotective activity of ethanol extract of Ziziphus mauritiana leaf against $\mathrm{CCl}_{4^{-}}$ induced liver damage in rats and the antidiarrhoea activity of the methanol root extract were reported (Dahiru et al., 2005; Dahiru et al., 2006). Based on the knowledge that antioxidants of plant origin are capable of modulating the effect of oxidative stress. The aims and objectives of this study was to evaluate the antioxidant effect of the aqueous extract of Ziziphus mauritiana leaf on chronic alcohol-induced hepatotoxicity.

\section{Materials and Methods Plant Preparation}

Fresh leaf of Ziziphus mauritiana was collected 20km along Yola-Mubi road in the month of July 2005. Identification of the plant material was done by Bristone Basiri at the department of Botany Federal University of Technology, Yola. A voucher specimen of the plant has been deposited (BCDD-03b) in the Department of Biochemistry Federal University of Technology, Yola. The leaves were shed dried under room temperature at $30 \pm 2^{\circ} \mathrm{C}$ for 7 days. The dried material was made into powder using mortar and pestle and sieved with Endicott test sieve $0.3 \mathrm{~mm}$ (Endicott Ltd, London). $100 \mathrm{~g}$ of the powdered plant material was steeped in 600 $\mathrm{ml}$ of distilled water and placed in water bath for 3 hours at $90^{\circ} \mathrm{C}$. The mixture was allowed to cool to room temperature and filtered. The filtrate was later freeze-dried yielding a residue corresponding to $22.56 \pm$ $1.72 \mathrm{~g} / 100 \mathrm{~g}$. 200 or $400 \mathrm{mg} / \mathrm{kg}$ body weight (bw) of the extract was used to pre-treat rats $30 \mathrm{~min}$ before alcohol administration.

\section{Experimental Design}

Thirty six male Wistar albino rats weighing between 100-120 g were purchased from the animal house of Faculty of Medical Sciences University of Jos. The animals were kept under standard condition of 12/12 h dark light circle and were fed with standard feed (Grand Cereals and Oil Mills, Ltd, Jos) and water ad libitum. The animals were allowed to acclimatize for two weeks before being distributed into different groups of six rats each and treated for six weeks as follows:

Group I - rats in addition to normal diet were given $1 \mathrm{ml} / 100 \mathrm{~g}$ bw normal saline. Group II - rats in addition to normal diet received $40 \%$ alcohol solution (v/v, $1 \mathrm{ml} / 100 \mathrm{~g}$ bw, p.o). Group III, IV and V in addition to normal diet were pretreated with either $200,400 \mathrm{mg} / \mathrm{kg}$ bw aqueous extract of Z. mauritiana leaf or 100 $\mathrm{mg} / \mathrm{kg}$ bw silymarin (reference hepatoprotective material) respectively, $30 \mathrm{~min}$ before feeding rats with $40 \%$ alcohol solution ( $\mathrm{v} / \mathrm{v}, 1 \mathrm{ml} / 100 \mathrm{~g}$ bw). Group VI - rats were administered $400 \mathrm{mg} / \mathrm{kg}$ bw aqueous extract of $Z$. mauritiana in addition to normal diet.

\section{Biochemical estimations}

At the end of the treatment period, rats were sacrificed under light ether anesthesia and blood collected via the ocular vein without the use of anticoagulant. The blood was allowed to stand for $10 \mathrm{~min}$ before being centrifuged at 2,000 rpm for $10 \mathrm{~min}$ to obtain serum for analysis. The levels of alkaline phosphatase (ALP), alanine aminotransferase (ALT), aspartate aminotransferase (AST) and total bilirubin (TB) were assayed using Randox clinical test kits (Randox Ransod, Laboratories, Ltd U.K.). Rats were dissected, liver removed and placed on ice bath. $1 \mathrm{~g}$ portion of the liver was used to prepare homogenate of the liver $(10 \%)$ in ice cold potassium chloride $(\mathrm{KCl})$ solution $(1.15 \% \mathrm{w} / \mathrm{v})$, using Teflon homogenizer. The homogenate was centrifuge at $4000 \mathrm{~g}$ for $10 \mathrm{~min}$ to remove nuclear fraction. The supernatant was used for the estimation of antioxidant enzymes glutathione reductase, glutathione peroxidase and superoxide dismutase and catalase using test kits (Randox, Ransod Ltd, UK). 


\section{Histopathological evaluation}

Liver tissue was collected for histopathological analysis; a portion of the liver was fixed in $10 \%$ formalin, processed using routine histology procedures and embedded in liquid paraffin. The liver tissue was then cut into 5 $\mu \mathrm{m}$ sections and mounted on a slide. The samples were stained with hematoxylin and eosin for histopathological examination.

\section{Results}

Table 1 represents the result of pre-treatment on enzyme and non-enzyme markers of tissue damage. Exposure of rats to alcohol for six weeks showed significant $(\mathrm{p}<0.05)$ elevated levels of AST, ALT, ALP, and TB. Pre-treatment of rats with 200 or $400 \mathrm{mg} / \mathrm{kg}$ bw aqueous extract of Ziziphus mauritiana leaf showed a significant $(\mathrm{p}<0.05)$ dose-dependent decreased levels of AST, ALT, ALP, and TB.

Table 2, represents the result of pre-treatment with or without aqueous extract of Ziziphus mauritiana on hepatic antioxidant enzymes. Ingestion of alcohol only by rats resulted in a significant $(p<0.05)$, decreased levels of glutathione reductase, glutathione peroxidase, catalase and superoxide dismutase. Pre-treatment of rats with the extract of Ziziphus mauritiana raised significantly $(\mathrm{p}<0.05)$ the levels of these enzymes.

Histopathological sections of normal liver (Figure 1) show structural integrity without necrosis, inflammation, mononuclear cell aggregation, thrombus or fatty degeneration. Liver of rat ingested with chronic alcohol for 6 weeks (figure 2) reveals severe necrosis, general and focal inflammations, cytoplasmic vacuolization, mononuclear cell aggregation and fatty degeneration in the central and mid zonal areas, which confirms the severity of damaged liver due to chronic alcohol ingestion. Liver of rats pre-treated with aqueous extract of Ziziphus mauritiana or silymarin (figures 3,4 and 5 respectively) showed reduced formation of necrosis, inflammation, mononuclear cells aggregation and fatty degeneration to about the pathology of a normal liver tissue.

Table 1: Effect of Pre-treatment with Ziziphus mauritiana aqueous leaf extract on serum markers of tissue damage in chronic alcohol fed rats

\begin{tabular}{|c|c|c|c|c|}
\hline & AST (U/L) & $\operatorname{ALT}(\mathrm{U} / \mathrm{L})$ & $\operatorname{ALP}(\mathrm{U} / \mathrm{L})$ & $\mathrm{TB}(\mathrm{mg} / \mathrm{dl})$ \\
\hline Normal & $36.04 \pm 2.88$ & $22.76 \pm 1.77$ & $921.18 \pm 28.94$ & $0.012 \pm .00$ \\
\hline Alcohol & $59.14 \pm 4.55^{\mathrm{d}}$ & $38.30 \pm 2.23$ & $2168.93 \pm 104.95^{\mathrm{d}}$ & $0.635 \pm 0.03^{\mathrm{d}}$ \\
\hline $\mathrm{Zm} \mathrm{200mg/kg}+\mathrm{Alc}$ & $46.16 \pm 2.74^{\mathrm{e}}$ & $31.02 \pm 3.09^{\mathrm{e}}$ & $1731.95 \pm 142.05^{\mathrm{e}}$ & $0.045 \pm 0.07^{\mathrm{e}}$ \\
\hline $\mathrm{Zm} 400 \mathrm{mg} / \mathrm{kg}+\mathrm{Alc}$ & $36.16 \pm 2.11^{\mathrm{ef}}$ & $26.00 \pm 2.10^{\text {ef }}$ & $1349.71 \pm 145.59^{\text {ef }}$ & $0.140 \pm 0.01^{\text {ef }}$ \\
\hline Sily $100 \mathrm{mg} / \mathrm{kg}+\mathrm{Alc}$ & $36.72 \pm 1.90^{\mathrm{ef}}$ & $24.94 \pm 1.17^{\text {ef }}$ & $1268.31 \pm 84.52^{\mathrm{ef}}$ & $0.097 \pm 0.04^{\mathrm{ef}}$ \\
\hline $\mathrm{Zm} 400 \mathrm{mg} / \mathrm{kg}$ & $34.24 \pm 2.14$ & $20.88 \pm 1.82$ & $945.35 \pm 36.71$ & $0.011 \pm 0.01$ \\
\hline
\end{tabular}

Results are Mean \pm S.D, $(n=5)$. ${ }^{d}$ Significantly higher compared to control group $(\mathrm{p}<0.05)$. ${ }^{\mathrm{e}}$ Significantly lower compared to experimental group $(\mathrm{p}<0.05)$. ${ }^{\mathrm{f}}$ Significantly lower compared to group pretreated with $200 \mathrm{mg} / \mathrm{kg}$ bw extract.

Table 2: Result of pre-treatment with or without aqueous extract of Ziziphus mauritiana leaf extract on hepatic antioxidant enzymes

\begin{tabular}{lcccc}
\hline Treatment & $\begin{array}{c}\text { GR } \\
\text { (U/mg liver) }\end{array}$ & $\begin{array}{c}\text { GPx } \\
\text { (U/mg liver) }\end{array}$ & $\begin{array}{c}\text { SOD } \\
\text { (U/mg liver) }\end{array}$ & $\begin{array}{c}\text { CAT } \\
\text { (U/mg liver) }\end{array}$ \\
\hline Normal & $55.58 \pm 2.72$ & $37.94 \pm 3.14$ & $10.35 \pm 1.30$ & $66.68 \pm 3.96$ \\
Alcohol & $28.53 \pm 1.28^{\alpha}$ & $17.78 \pm 2.18^{\alpha}$ & $3.69 \pm 1.00^{\alpha}$ & $38.83 \pm 1.47^{\alpha}$ \\
Zm 200mg/kg + Alc & $38.52 \pm 3.14^{\beta}$ & $26.86 \pm 1.53^{\beta}$ & $6.10 \pm 1.24^{\beta}$ & $48.93 \pm 1.99^{\beta}$ \\
Zm 400mg/kg + Alc & $47.14 \pm 3.99^{\beta c}$ & $31.07 \pm 2.40^{\beta c}$ & $9.17 \pm 1.20^{\beta c}$ & $58.90 \pm 1.52^{\beta c}$ \\
sily 100mg/kg + Alc & $49.49 \pm 3.27^{\beta c}$ & $34.52 \pm 3.18^{\beta c}$ & $8.97 \pm 1.32^{\beta c}$ & $55.08 \pm 1.08^{\beta c}$ \\
\hline
\end{tabular}

Results are Mean \pm S.D, $(n=5) .{ }^{\alpha}$ Significantly lower than control $(\mathrm{p}<0.05) .{ }^{\beta}$ Significantly higher compared to experimental group $(\mathrm{p}<0.05)$. ${ }^{\mathrm{C}}$ Significantly higher compared to group pretreated with $200 \mathrm{mg} / \mathrm{kg}$ bw extract $(\mathrm{p}<0.05)$. 


\section{Discussion}

Reactive oxygen species (ROS) are highly reactive intermediates generated during ethanol oxidation via CYP2E1 that contributes to ethanol-induced liver injury (Hoek and Pastorino, 2002; Jaeschke et al., 2002). In addition the increased formation of reactive oxygen species, such as hydrogen peroxide $\left(\mathrm{H}_{2} \mathrm{O}_{2}\right)$ and superoxide anion $\left(\mathrm{O}_{2}{ }^{\circ}\right)$ have been implicated as a cause of liver injury in various forms of chronic liver disease including alcoholic liver diseases (Parola and Robino, 2001). Reactive oxygen species are highly reactive and can damage lipids, proteins and DNA (Arteel, 2003).

Chronic alcohol administration was observed to cause marked injury to the liver cells of rats. Serum bilirubin and activities of AST and ALT are the most sensitive tests employed in the diagnosis of hepatic diseases. Increased level of alkaline phosphatase has been attributed to the damaged structural integrity of hepatic cells because the enzyme alkaline phosphatase is located in the cytoplasm and is released into the circulation after cellular damage (Sallie et al., 1991). If injury involves organelles, such as mitochondria then the soluble enzymes such as AST compartmented will also be similarly released indicating membrane damage (Rajagopal et al., 2003). Previous reports have shown that exposure of hepatocytes to ethanol perturbs the membrane structure and functions thereby increasing the leakage of AST (Rajakrishnan and Menon, 2001). Bilirubin, an endogenous organic anion binds reversibly to albumin and it is transported to the liver, and then conjugated with glucuronic acid and excreted in the bile. Hepatobilliary disease is indicated when bilirubin fraction exceeds normal (Rosen and Keefe, 1998). Increased bilirubin content in serum reflects the pathophysiology of the liver. Therefore, hyperbilirubinaemia is one of the most sensitive and useful test to substantiate the functional integrity of the liver and severity of necrosis. It measures the binding, conjugating and excretory capacity of hepatocytes that is proportional to the erythrocytes degradation rate (Singh et al., 2005). An increased level of total bilirubin reflects depth of jaundice and increased aminotransferases and alkaline phosphatase were the clear manifestation of cellular leakage and loss of functional integrity of the cell (Saroswat, 1993). Rats pre-treated with aqueous extracts of Ziziphus mauritiana leaf prior to alcohol ingestion resulted in a significant decreased levels of AST, ALT, ALP, TB and UA in a dose dependent manner compared to rats treated with alcohol only. This indicates that pre-treatment with the aqueous extract of Ziziphus mauritiana leaf prior to ethanol administration might have protected both plasma membrane and liver cells against membrane damage due to alcohol toxicity and thereby, decreasing the leakage of serum enzyme markers into the circulation. The low levels of the enzymes are a reflection of protection conferred against the hepatic damage caused by the hepatotoxin (Vogel, 2002). Ingestion of the highest dose of aqueous extracts of Ziziphus mauritiana leaf only by rats did not show any significant difference in AST, ALT or ALP enzymes compared to normal rats. This is an indication that the extract (doses used) had no adverse effect on the plasma membrane or organelle membranes of rats. It is possible that pre-treatment prior to alcohol administration allows the active principle in the extract to reach its target site or the extract might have inhibited the absorption of alcohol from the stomach to the liver. It is also possible that pre-treatment of rats with the extract prior to alcohol administration boosted the antioxidant capacity of the rats before alcohol ingestion. Decreased levels of serum AST, ALT, ALP and total bilirubin in rats pretreated with methanol extract of Ziziphus mauritiana leaf prior to $\mathrm{CCl}_{4}$ toxicity had been reported (Dahiru et al., 2005).

Decrease activity of superoxide dismutase, catalase and glutathione peroxidase is very important because it may lead to breakdown in the antioxidant barrier. Superoxide dismutase catalysis the reaction of superoxide anion radicals $\left(\mathrm{O}_{2}{ }^{\circ}\right)$ dismutation to hydrogen peroxide $\left(\mathrm{H}_{2} \mathrm{O}_{2}\right)$, whereas catalase degrades $\mathrm{H}_{2} \mathrm{O}_{2}$ into a molecule of oxygen and water (McCord, 2000; Saravanan et al., 2003). Superoxide ion $\left(\mathrm{O}_{2}{ }^{\circ}\right)$ and hydroxyl radicals are known to cause marked injuries to the surrounding tissues and organs. Therefore removing superoxide ion and hydroxyl radicals is probably one of the most effective defense mechanisms against a variety of diseases. Lowered activities of superoxide dismutase, catalase and glutathione peroxidase will result in the accumulation of these highly reactive free radicals leading to deleterious effects such as loss of cell membrane integrity and membrane function (Sheela and Angusti, 1995; Krishnakantha and Lokesh, 1993). Oxidant scavenging at the intracellular level within the cytosol appears to rely on glutathione peroxidase for elimination of low molecular levels of hydroperoxides and lipid peroxidation (Suttorp et al., 1986). Decreased level of glutathione peroxidase in the liver of rats that ingested alcohol could be due to either free radical dependent inactivation of enzyme or depletion of its co-substrates, that is GSH and NADPH. Catalase activity was decreased in alcohol exposed rats which could possibly be due to loss of NADPH, or generation of superoxide, or increased activity of lipid peroxidation or combination of all (Chandra et al., 2000; Das and Vasudevan, 2005). Pretreatment of rats with aqueous extract of Ziziphus mauritiana leaf prior to alcohol ingestion resulted in significant increased levels of glutathione reductase, glutathione peroxidase, superoxide dismutase and catalase compared to rats that ingested alcohol only. Increased levels of these antioxidant enzymes due to pretreatment of rats with aqueous extract of Ziziphus mauritiana leaf indicates that the extract contain compounds that converted free radicals to more stable products or due to direct stimulatory effect of the extract on the antioxidant enzymes studied. 


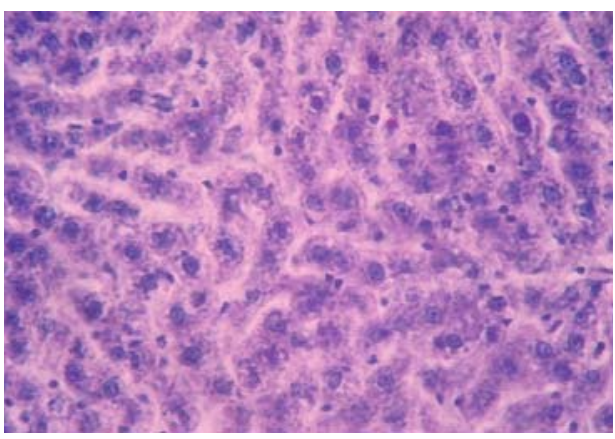

Figure 1: Histology of normal liver tissue from control rat liver (H \& E; x650)

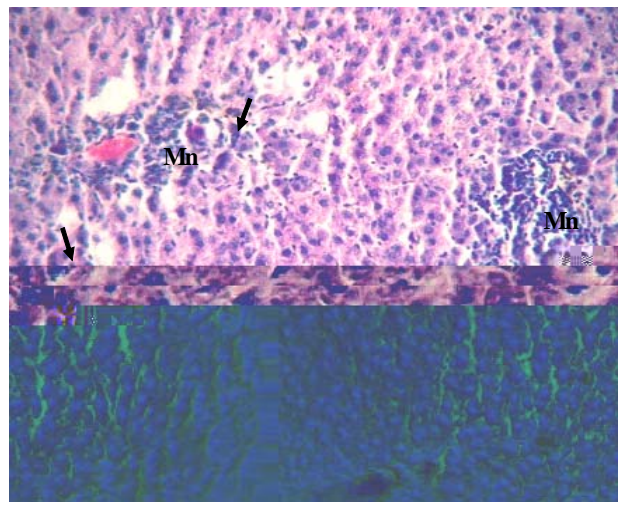

Figure 2: Liver tissue of rat administered alcohol only showing periportal hepatic necrosis, mononuclear cellular aggregations $(\mathrm{Mn})$ and presence of scattered megalocytes and multinucleated hepatocytes (arrows) [note presence of thrombus in the periportal vein](H \& E; x650)

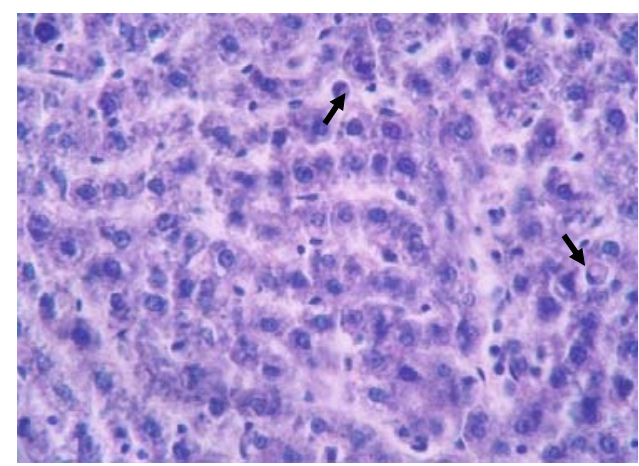

Figure 3: Liver tissue of rat pre-treated with $200 \mathrm{mg} / \mathrm{kg}$ bw aqueous extract of Ziziphus mauritiana leaf showing an apparently normal liver with few scattered hepatocytes with vacuoles and pyknotic nuclei (arrows) (H \& E; x650)

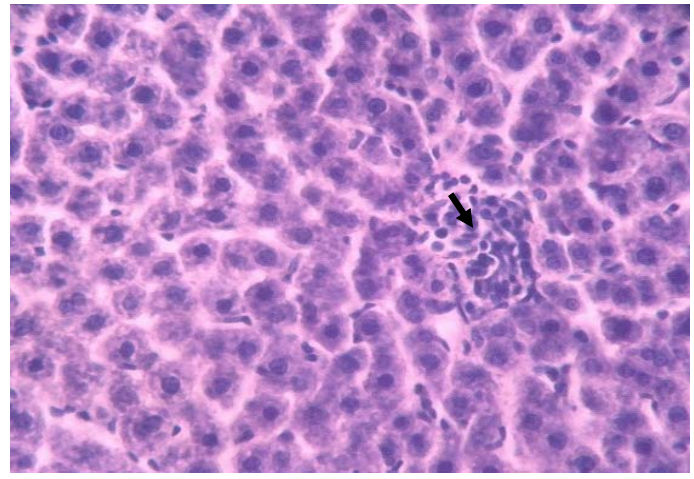

Figure 4: Liver tissue of rat pre-treated with $400 \mathrm{mg} / \mathrm{kg}$ bw aqueous extract of Ziziphus mauritiana leaf showing an apparently normal liver with a focal area of mild mononuclear periportal cell aggregate (arrow)(H \& E; x650

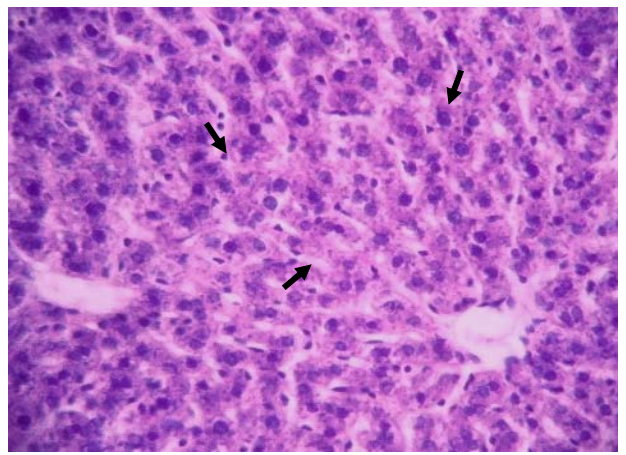

Figure 5: Liver tissue of rat pre-treated with silymarin before alcohol administration showing an apparently normal organ with very few hepatocytes with tiny cytoplasmic vacuoles (arrows) (H\& E; x650

Histopathological changes observed in the liver of alcohol treated rats were predominantly in the centrilobular region having reduced oxygen perfusion (Sakar et al., 1995). The development of alcoholic liver disease may progress as a function of the rate of cell death over the rate at which the damage can be repaired. This would particularly be the case in processes where necrosis is the predominant mode of cell death, as 
opposed to programmed cell death (Young et al., 2006). Morphological changes in fat accumulation were also observed in rats fed alcohol only. Chronic alcohol consumption exhibited typical signs of fatty liver, with accumulations in fat droplets throughout. It is known that fat accumulation in the liver is a multi-factorial phenomenon thought to be caused by a blockage of lipoproteins secretions; impaired synthesis or peroxidation of phospholipids, or both (Junnila et al., 2000). Pretreatment of rats with $400 \mathrm{mg} / \mathrm{kg}$ bw aqueous extract of Ziziphus mauritiana leaf was more effective in protecting rats against necrosis and thrombosis due to chronic alcohol ingestion when compared with $200 \mathrm{mg} / \mathrm{kg}$ bw aqueous extract of Ziziphus mauritiana leaf. Morphological changes in fat accumulation were improved by pretreatment with aqueous extract of Ziziphus mauritiana leaf or pretreatment with silymarin.

Phytochemical compounds present in the aqueous extract of Ziziphus mauritiana leaf with possible antioxidant activity are tannins, phenolic compounds and flavonoids. Tannins are known to exert antihepatotoxic action (Hikino et al., 1985). The basis for the hepatoprotective action of tannins has been attributed to the formation of an impervious polyphenol-protein and /or polysaccharide layer under which the natural healing process can occur (Haslem et al., 1988). Polyphenolic compounds have been shown to protect various cell types from oxidative stress mediated cell injury (Sasaki et al., 2002). The polyphenolic structures of flavonoids partition into the hydrophobic core of the membrane can cause a modulation of lipid fluidity (Arti et al., 2000). Flavonoids have been reported to inhibit peroxidation of polyunsaturated fatty acids in cell membranes (Faure et al., 1990). These substances, could react with the deeper membrane domains and intracellular structures, and protect the cells from oxidant injury (Kaviarasan et al., 2006).

In conclusion, aqueous extract of Ziziphus mauritiana leaf is effective against oxidative liver damage induced by chronic alcohol administration. The protective effect of the extract was possibly achieved through radical scavenging of free radicals by antioxidant enzymes.

\section{Acknowledgement}

The authors are grateful to Prof. Taiwo Victor for his kind assistance in relation to the histopathology of the liver tissue during his sabbatical leave at the University of Maiduguri, Nigeria.

\section{References}

1. Arteel, G.E. (2003). Oxidants and antioxidants in alcoholic liver disease. Gastroenterol; 124: 778-790.

2. Arti, A., Byren, T.M. and Nair, M.G. (2000). Modulation of liposomal membrane fluidity by flavonoids and isoflavonoids. Arch Biochem Biophys; 373: 102-109.

3. Chandra, R., Aneja, R., Rewal, C., Konduri R, Das, S.K, and Agarwal, S. (2000). An opium alkaloid-Papaverine ameliorates ethanol-induced hepatotoxicity: diminution of oxidative stress. Ind. J. Clin Biochem. 15(2): 155-160.

4. Dahiru, D., Sini, J.M. and John-Africa, L. (2006) Antidiarrhoeal activity of Ziziphus mauritiana root extract in rodents. Afr J. Biotechnol., 5(10): 941-945

5. Dahiru, D. William, E.T. and Nadro, M.S. (2005). Protective effect of Ziziphus mauritiana leaf extract on carbon tetrachloride-induced liver injury. Afr J. Biotechnol., 4(10): 1177-1179.

6. Das, S.K. and Vasudevan, D.M. (2005). Effect of ethanol on liver antioxidant defense systems: a dose dependent study. Ind. J. Clin. Biochem., 20(1): 79-83.

7. Das, S.K. and Vasudevan, D.M. (2006). Effect of lecithin in the treatment of ethanol mediated free radical induced hepatotoxicity. Ind J. Clin Biochem., 21(1): 62-69.

8. Faure, P., Rousel, M.A., Richard, M.J. (1990). Effect of an acute Zinc depletion on rat lipoprotein distribution and peroxidation. Biol Trace Ele Res., 28: 134-146.

9. Friedman, S.L. (1983). Seminars in medicine of the Beth Israel Hospital, Boston. The cellular basis of hepatic fibrosis. Mechanism and treatment strategies. New Eng J Med., 328: 1828-1835.

10. Haslem, E., Lilley, T.H., Ya, C., Martin, R. and Magnolat, O. (1988). Traditional herbal medicines-The role of polyphenols. Planta Medica., 55: 1-8.

11. Hikino, H., Kiso, V., Hatano, T., Yoshida, T. and Okuda, T. (1985). Antihepatotoxic action of tannins. J Ethnopharmacol., 14: 19-29.

12. Hoek, J.B. and Pastorino, J.G. (2002). Ethanol, oxidative stress and cytokine-induced liver cell injury. Alcohol, 27:63-68.

13. Ishii, H., Kurose, I. and Kato, S. (1997). Pathogenesis of alcoholic liver disease with particular emphasis on oxidative stress. J Gastroenterol Hepatol., 12(9-10): S272-282.

14. Jaeschke H, Gores GJ, Cederbaum AI, Hinson JA, Pessayre D and Lemasters JJ (2002). Mechanisms of hepatotoxicity. Toxicol. Sci., 65:169-176.

15. Junnila M, Rahko T, Sukura A. and Lindberg LA. (2000). Reduction of carbon tetrachloride-induced hepatotoxic effects by oral administration of betane in male Han-Wistar rats: a morphometric histological study. Vet. Pathol., 37(3): 231-238. 
16. Kaviarasan, S., Ramamurty, N., Gunasekaran, P., Varalakshmi, E. and Anuradha, C.V. (2006). Fenugreek (Trigonella foenum graecum) seed extract prevents ethanol-induced toxicity and apoptosis in chang liver cells. Alc alcohol., 41(3):267-273.

17. Kim, Y.H. and Shin, M.J. (2002). Effect of High taurocholate load on activities of hepatic alcohol metabolizing enzymes. Exp Mol Med,. 34: 123-130.

18. Krishnakantha, T.P. and Lokesh, B.R. (1993). Scavenging of superoxide anion by spice principles. Ind J Exp Biol., 30: 133-134.

19. Lieber, C.S. (2000). Alcohol and the liver: Metabolism of alcohol and its role in hepatic and extrahepatic diseases. Mt Sinai J. Med., 67: 84-94.

20. McCord, J.M. (2002). The elevation of free radicals and oxidative stress. Am J Med., 108: 652-659.

21. Michel, A. (2002). Tree, Shrub and Liana of West African Zone. Margraf Publishers GMBH, Paris. pp 440.

22. Morton, J. (1987): Indian Jujube. In: Fruits of warm climates. Morton, J. F. (ed), Miami, Florida. 272-275. Last updated: 23/4/2004. Accessed on 5/5/2004 at http://www.Indian jujube.htm

23. Nadro, M.S., Arungbemi, R.M. and Dahiru, D. (2006). Evaluation of Moringa oleifera lelaf extract on alcoholinduced hepatotoxicity. Trop J. Pharmaceut Res., 5(1): 539-544.

24. Parola, M. and Robino, G. (2001). Oxidative stress related molecules and liver fibrosis. J. Hepatol., 35: 297-306.

25. Pronko, P., Bardina, L., Satanovskaya, V. Kuzmich, A. and Zimatkin, S. (2002). Effect of alcohol on metabolizing systems in the rat gastrointestinal tract. Alcohol Alcohol., 37: 229-235.

26. Puzziferri, I., Signorile, A., Guerrieri, F., Papa, S., Cuomo, V. and Steard, O. (2000). Chronic low dose ethanol intake: biochemical characterization of liver mitochondria in rats. Life Sci., 66: 477-484.

27. Quertermont, E. (2004). Genetic polymorphism in ethanol metabolism: acetaldehyde contribution to alcohol abuse and alcoholism. Mol Psychiatry., 9(6): 570-581.

28. Rajagopal, S.K., Manickam, P., Periyasamy, V. and Namasivayam, N. (2003). Activity of Cassia auriculata leaf extract in rats with alcoholic liver injury. J. Nutr Biochem., 14: 452-458.

29. Rajakrishnan, V. and Menon, V.P. (2001). Potential role of antioxidants during ethanol induced changes in the fatty acid composition and arachidonic acid metabolites in male Wistar rats. Cell Biol Toxicol., 17: 11-22.

30. Rosen, H.R., and Keefe, E.B. (1998). Laboratory evaluation of patients with signs and symptoms of liver disease. In clinical practice of gastroenterology (Brandt, L.J. Ed), Churchil Livingstone, Philadelphia. 812-820pp

31. Sakar, S.N., Chattopadhyay, S.K., Majmudar, A.C. (1995). Sub-acute toxicity of urea herbicide, isoproturon in male rats. Ind J Exp Biol., 33: 851-856.

32. Sallie, R., Tredger, J.M. and William, R. (1991). Drugs and the liver. Biopharmaceut Drug Disposit., 12: 251 259.

33. Saravanan, R., Rajendra, N., Prasad, N.R., Pugalendi, K.V. (2003): Effect of Piper betle leaf extract on alcohol toxicity in the rat brain. J Med Food., 6(3): 261-265.

34. Saroswat, B., Visen, P.K., Patnalik, G.K. and Dhawan, B.N. (1993). Anticholestic effect of picroliv, active hepatoprotective principle of Picrorhizza kurrooa, against carbon tetrachloride induced cholestasis. Ind J. Exp Biol., 31: 316-318.

35. Sasaki, N., Toda, T., Kaneko, T., Baba, N. and Matsuo, M. (2002). Flavonoids suppress the cytotoxicity of linoleic acid hydroperoxide toward PC12 cells. Biol Pharm Bull., 25: 1093-1096.

36. Sheela, C.G. and Angusti, K.T. (1995). Antiperoxide effects of s-allyl cysteine sulphoxide isolated from Allium sativum Linn and gugu lipid in cholesterol diet fed rats. Ind J Exp Biol., 33: 337-341.

37. Singh, B., Chandan, B.K., Prabhakar, A., Taneja, J., Singh, J. and Qazi, N. (2005). Chemistry and hepatoprotective activity of an active fraction from Barteria prionitis Linn in experimental animals. Phytother Res., 19: 391-404.

38. Suttorp, H., Toepfer, W. and Roka, L. (1986). Antioxidant defense mechanisms of endothelial cells: glutathione redox cycle versus catalase. Am J Physiol; 251: 671-680.

39. Vidal, F., Toda, R., Gutierrez, C., Broch, M., Fernandez-Muixi, F., Lorenzo, A. and Richart, C. (1998). Influence of chronic alcohol abuse and liver disease on hepatic aldehyde dehydrogenase activity. Alcohol; 15: 3-8.

40. Vogel, H.G. (2002). Carbon tetrachloride induced liver fibrosis in rats. In Drug Discovery and Evaluation, Pharmacological assays, $2^{\text {nd }}$ edn. Vogel HG, Vogel WH (eds). Springer Verlag: Berlin. 942pp

41. $\mathrm{Wu}, \mathrm{D}$. and Cederbaum, A.I. (2003). Alcohol, oxidative stress and free radical damage. Alc Res Health., 27(4):277-284

42. Young, A.T., Bailey, S.M., VanHorn, C.G. and Cunningham, C.C. (2006). Chronic ethanol consumption decreases mitochondrial and glycolytic production of ATP in liver. Alc alcohol, 41(3): 254-260.

43. Zhou, Z., Sun, X. and Kang, J.Y. (2003). Methionine Protection against Alcohol Liver Injury through Inhibition of Oxidative Stress. Exp Biol Med, 222(3): 214-222. 